\title{
The (re)production of the exploitative nature of rural migrant labour in Europe
}

\author{
Karen O'Reilly and Johan Fredrik Rye
}

\section{Practice stories of international labour migration}

This chapter draws across the major contributions of this edited volume to thread together a 'practice story' (O'Reilly 2012) of international labour migration to Europe's rural regions. Our starting point was our desire to explain the generally exploitative wage, working, and living conditions experienced by rural migrant workers, as described in several of the present volume's chapters as well as in the wider literature; conditions which appear to be perpetually reproduced irrespective of efforts of migrants or others to improve the situation (see for instance, Bock et al. 2016, Rye and Scott 2018, Corrado et al. 2016, Gertel and Sippel, eds. 2014). Our account in this chapter reveals how the daily practices of agency (of all agents involved in the process at whatever level) work to (re)produce the internal and external structural conditions that are well known to give rise to generally exploitative working conditions.

In Chapter 1 of this volume, we argued for a multiscalar and multidimensional approach to the field, where the ongoing outcomes of labour migration are understood to emerge out of the interaction between everyday practices of actors and the dynamics of local, regional, national, European, and global societal structures. To achieve coherence in this endeavour, in this chapter we employ the meta-theoretical framework of practice stories (O'Reilly 2012), informed by strong structuration theory (Stones 2005) to frame a substantive understanding of the processes involved in this phenomenon. Strong structuration theory understands the making of the social world as ongoing processes, both shaped by and shaping of general patterns, arrangements, and other external social structures. It explicates the ways in which cultures, behaviours, attitudes, institutions, and other sociological phenomena develop over time as norms, rules, organisational arrangements, and other internal structures are acted on and adapted by individuals through the performance of their daily lives, in the context of their communities, groups, networks, and families.

The discussion is organised in three sections. First, we outline our explanandum: the general conditions under which the migrants in this edited volume 
find themselves living and working. Second, we provide a necessarily brief account of the theoretical construct of practice stories and the structuration theory framework on which it builds. Third, we apply this conceptual framework to identify key elements in the making of the contemporary phenomenon of international labour migration to Europe's rural regions, in terms of structural forces, individual agency, practices, and outcomes. We illustrate how the social practices of the agents - migrants and others involved in the phenomenon - often lead to the reproduction of exploitative practices.

In conclusion, our analysis demonstrates how the rural labour migration phenomenon has developed from macro-level circumstances under which improved wage, working, and living conditions are difficult or impossible to achieve; meso-level developments continue to operationalise assumptions that labour migration is necessarily harsh and that employers need to be protected; employers and other powerful agents embody the normalisation of exploitative practices; and even the migrants themselves come to accommodate, or reproduce, their own marginalised, subordinated, and invisible status.

\section{The explanandum: exploitative wage, working, and living conditions}

The everyday life of labour migrants in Europe's rural regions is generally inscribed with exploitative wage, working, and living conditions. As noted in the review of the literature in the first chapter of the book, this follows from the very characteristics of the jobs they tend to perform. Work tasks are difficult, dirty, and often dangerous, and overall labour relations resemble those of the secondary labour market: low-paid and low-status jobs, substandard working conditions, including exposure to health hazards, high instability of employment, lack of promotion and training opportunities, and contracts between employers and employees that are too often based on informal and personal relationships (Doeringer and Piore 1971, Holmes 2013). Conditions at work are mirrored in migrants' marginal, subordinate, and often invisible positions in the various rural communities to which they arrive, even acknowledging that rural communities are themselves diverse, complex, and difficult to define, as we argue in the first chapter of this edited volume.

While the chaptersin thisedited volume add detail and depth to an understanding of the rural labour migrants' plight, they also emphasise common themes. These include: the vulnerable position of migrants and the continuous replacement of migrant labour with new arrivals and different ethnic groups (Farinella and Nori, Chapter 5), and the 'subordinated inclusion' of migrant workers, where rights with regards to wages and contracts are not implemented in practice despite collective agreements (Tollefsen et al., Chapter 8). In Poland there is 'low attractiveness of agriculture for incoming migrants in terms of relatively low wages and high workload' (Górny and Kaczmarczyk, Chapter 6, 86). Șerban et al. (Chapter 2,30) describe the work of Romanian strawberry pickers in Huelva as 
'difficult and physically exhausting... supervision was tight and migrants shared a perception of "being watched"... the housing offered was isolated... sleeping three to seven in a room.' Brovia and Piro (Chapter 4) illustrate how isolation in camp and dormitory living means the worker is available at all times of day and night, with little privacy from other migrants or from the employer. These workers have little opportunity to improve their conditions or to go elsewhere, especially given their salaries can be held over until the end of the season. Thai berry pickers in Sweden (Tollefsen et al., Chapter 8) are subject to diverse practices such as employers refusing to let them work once the fridges are full and confiscating car keys to ensure they can't go elsewhere. Farinella and Nori (Chapter 5) describe the dependency, subordination, isolation, and solitude that are typical features of life for immigrant shepherds, despite the fact they also have a great deal of autonomy and freedom in their work, managing much of their workday alone and unsupervised. And Stachowski and Fiałkowska (Chapter 7) describe the spatial separation of Polish migrants in Germany into an 'army of goblins,' invisible to local communities because they are housed close to where they work, often in cramped containers, rather than in proper housing in residential areas.

Our goal in this chapter is to attempt to explain this ongoing exploitation, the perpetual reproduction and augmentation of labour arrangements that are asymmetric in terms of power relations, working conditions, and outcomes. The rural labour migrants in the pages of this book move to new destinations in search of better employment conditions than they would have at home, and they arrive under conditions already set in favour of employers. Our task here is to ask: what are the processes that work to reproduce this ongoing cycle of exploitation?

\section{Informing a practice story of rural labour migration}

The goal of a practice story is to offer a substantive interpretation of a phenomenon that is faithful to understandings that structure and agency interact over time and space through the ongoing practice of everyday life. Our approach here owes a special debt to the work of Stones (2005) who developed a stronger version of structuration theory that builds on and develops the work of Giddens and Bourdieu and others (and see Greenhalgh et al. 2014 and Stones et al. 2019). This strong structuration theory (SST) was then specifically developed by O'Reilly (2012) for the study of migration. Employing practice stories to shape an understanding of a substantive phenomenon involves drawing attention to the following heuristically discrete elements that we will examine in more detail as we proceed:

i) Upper structural, or macro-level, layers that frame actions (O'Reilly 2012, 23-25).

ii) The more proximate or meso-level structures that may be somewhat malleable by the agents in focus (O'Reilly 2012, 23-25, and see Morawska 2009). 
iii) Habitus (cf. Bourdieu 1990) and internal structures (O'Reilly 2012, 26-28).

iv) Practice, active agency, and conjuncturally specific internal structures (O'Reilly 2012, 26-28, and see Stones 2005), or the ways in which people adapt their habitus in daily life, within their relevant communities of practice (Lave and Wenger 1991).

v) Outcomes or newly (re)formed external and internal structures (O'Reilly 2012, 28-32, Emirbayer and Mische 1998).

We also use the concept of agent in focus (Stones 2005) to mean the given set of individuals and groups who are the main concern of the present analysis. In this chapter, as in most of the chapters in the present volume, the 'agents in focus' are the international labour migrants in Europe's rural regions. There is a fuller, in-depth discussion of the role of practice stories and strong structuration theory (SST) in migration research in Benson and O'Reilly (2018), O'Reilly (2012), and Stones et al. (2019).

Crucially, SST draws attention to social life as a process, and therefore seeks to frame interpretations of change, or transformations, over time and space. Practice stories, in their turn, offer narrative accounts of the empirical data to explicate these processes. In this chapter we use this approach to provide a coherent and integrated understanding of the continuous reproduction of rural migrants' poor wage and working conditions which goes beyond pure descriptions of social practices and structural forces. Importantly, the following analysis represents a coherent interpretation of the materials provided in the edited volume's individual chapters, and thus represents our perspective but not necessarily those of chapter authors.

\section{i) Broad structural particularities of international rural labour migration}

Here we examine the upper structural, or macro-level, layers that have shaped the current phenomenon of international migration in Europe's rural regions. These refer to deeply held assumptions, ideological frames, institutional arrangements, and geographical and material features, over which the current agents in focus (the migrants in the chapters here) had no direct control at the time they began their migration journey. While the structural context is far more complex than we possibly could account for here, the chapters in this volume offer important insights into key structural conditions such as general processes of globalisation, enhanced mobility patterns, and geopolitical events at the European level, such as the downfall of communist regimes and the EU enlargements, which we introduced in the first chapter of the volume. However, we find in the chapters in this edited volume three structural aspects especially important for understanding the distinctive features of the phenomenon of labour migration in Europe's rural areas and rural industries. 
The first of these is the changing fabric of state borders, in which an increasing reliance on (temporary) migrant labour has become an integral and taken-for-granted characteristic of rural industries in western societies (Chapter 1). More than most industries, food production has come to rely on a migratory labour force as much as migrant workers have come to rely on work mobility as a strategy for achieving a sustainable livelihood. This reliance is often ideologically framed in a positive vein, such as the 'triple win' approach (Șerban et al., Chapter 2, 23-24) which has become 'the most widespread argument for legitimising the initiation of new temporary, circular initiatives.' This approach assumes that circularity is beneficial for countries of origin, destinations, and for the migrants themselves. The latter, it is presupposed, prefer eventually to be able to return to their home countries and their families. Șerban et al.'s analysis in this volume (Chapter 2) is somewhat less optimistic. The institutionalisation of such a reliance on migrant labour has in turn informed regulatory efforts and governance regimes such as the EU's inner labour market with 'free' movement of workers, and a 'resurrection' of guest-worker schemes for citizens from non-EU countries (Castles 2006). The volume also provides other examples of how national borders have become porous, either as result of very direct, specific, and intentional policy measures to ease migration flows for instance how east/west political collaboration steered Russian migrants to Norway's fish-processing industry around the turn of the century (Aure and Riabova, Chapter 10) - or as aggregate effects of less rigid border controls.

Second, a general process of restructuring in Europe's rural industries, most evident in the agricultural industry, has led to increasing levels of polarisation, competition, and exploitation of workers. In Europe, as in the US, agricultural production 'is being concentrated on fewer and larger farms, that hire most of a country's farm workers... (with) a larger than ever reliance on farm workers from poorer countries' (Martin, Chapter 13). This edited volume presents several examples of how the gradual disappearance of small farms in favour of land concentration, monoculture, and intensive agriculture provides an important backdrop for the unfolding rural labour migration phenomenon. These developments are most evident in the labour-intensive horticulture industries in the Mediterranean countries but are also observed in other parts of Europe. For instance, Farinella and Nori (Chapter 5) describe how these processes of agricultural modernisation and the global integration of the agri-food chains also have led to an increasing demand for low-waged workers and the growing exploitation of migrants in the agropastorial segments of Mediterranean agriculture. Another example is how Poland's farms have increasingly turned to Ukrainian farm workers (Górny and Kaczmarczyk, Chapter 6). However, the picture includes important nuances, and in Europe there still exists a substantial share of smaller-scale economic entities and farms that are family run. For instance, Rye and Scott 
(Chapter 9, 142) note the extent of polarisation of the strawberry industry in western countries, in which:

At one extreme are the global corporations with involvements at all stages of the value chain, often backed by non-agricultural finance. At the other extreme is the family farmer cultivating a few hectares of berries and relying on direct sales to the consumer.

Third, distinctive characteristics of rural society tend to be invoked to justify the exploitation and marginalisation of migrant workers. Most important, work in rural industries tends to be seasonal and/or fluctuating, as is particularly evident in land-based, peripheral, or natural resource-based industries like the berry industry in Sweden (see Tollefsen et al., Chapter 8) and in the labour-intensive character of horticulture (Rye and Scott, Chapter 9). As a result, there seems to be a persistent exemption of rural migrant workers from rights granted to most other industries; as Martin (Chapter 13, 211) states, agriculture has historically been 'often exempted from or treated differently from other sectors under labour laws and social welfare programs.' The European case provides further examples where efforts to regulate conditions for migrant workers sometimes meet success (Rye 2017), but where formal regulations are often not realised by changes on the ground (Rye and Andrzejewska, 2010, Tollefsen et al., Chapter 8). Relatedly, the volume's chapters suggest that rural society itself has features that work to ascribe the labour migrants social and spatial marginalised positions in the host localities. This is most evidently described in relation to housing in chapters by Stachowski and Fiałkowska (Chapter 7) and Brovia and Piro (Chapter 4). The often circular pattern of rural labour migration in Europe (in contrast to the US, Martin, Chapter 13) adds to their social detachment from the rural communities. This is further enhanced by the spatial structure of much of the labour the migrants perform, which tends to take place out of sight of, and at a physical distance from, the local community (Chapter 1).

Finally, it is important to note that these structural properties - the characteristics of rural work, the availability of circular or temporary labour, and the features of rural society that work to marginalise migrants - also take shape in the form of deep-seated assumptions about the nature of work in rural areas on the part of government agents, migration bodies, and even sometimes in academic work, such as in the 'triple win' approach. Here we are talking about ideological frames that are so taken for granted they are barely expressed. The chapters in this edited volume have revealed how manual work in the rural industries is 'normalised' as more precarious than is presumed to be the case in other industries; it is therefore argued to be more difficult to ensure workers' rights. These assumptions inform decision-making on behalf of those with the power to effect change, as they tend to be invoked to justify the exploitation of migrant workers. 
In summary, as the chapters in this edited volume have shown, there are distinctive structural features that are unique to our understanding of the experiences, practices, and outcomes of international labour migration to Europe's rural regions, and as such, sets it apart from other migration phenomena.

\section{ii) Specific localised features of rural labour migration}

Next we look at more proximate or meso-level structural conditions that shape practices of rural labour migration: opportunities, limits, constraints, and pertinent ideological frames which pertain to a given situation, country, or locality (Morawska 1996). Several chapters in this volume refer to more localised or idiomatic conditions that have led (directly or indirectly) to increased international migration to rural areas, and thereafter continue to influence the experiences of the international labour migrants. Also, here we draw attention to three meso-level structures of particular interest for understanding the nature of international labour migration in rural Europe. These echo the macro structures discussed in the previous section and are decisive in understanding the heterogeneity of the phenomenon.

First, there is a diversity of labour migration regimes across the European continent that directly condition the migrants' access to Europe's rural regions. These are largely the domain of state level regulations, and thus raise concerns pertinent to national socio-political contexts. They are also constantly changing, despite efforts at the EU level to standardise this field of legislation, for instance through the seasonal worker directive. Nevertheless, one commonality across the various migration streams covered in this volume is that regimes and governance tend to be demand-driven, addressing employers' assumed need for labour in their provision of poor working conditions.

Second, there is diversity in labour market regulations and practices as enacted at the level of the nation-state, but a common trait is how authorities consistently overlook or ignore rural labour migrants' poor working and living conditions. Even when legislative intentions are good, or inscribed into law, it appears that state authorities are in many cases incapable of de facto regulating migrant labour for the actual improvement of the position of migrants. This is expressly argued in the chapter by Tollefsen et al. (Chapter 8), where they discuss migrants' 'subordinated inclusion.'

Related to the above, recruitment agencies also act as localised (proximate) structures shaping these migrations and contributing to their continued poor conditions. As Stachowski and Fiałkowska (Chapter 7, 107 ) argue, 'a bulk of migration has been organised as posted workers and through recruitment agencies, which was an effective way of avoiding collective agreements such as equal wages.' For others, much recruitment is by word of mouth, and through friends and relatives (Farinella and Nori, Chapter 5). Intimating our 
argument below, we note here how migrants' agency in turn consolidates the formation of ethnic niches and exclusion.

Third, there are a variety of local-specific features of rural societies that are explicitly connected to the hardships migrants experience. Europe's rural regions are dependent on employment in rural industries, either in agriculture or other industries that is likely to recruit migrant workers to low-skilled, manual jobs in global competitive branches. They also share processes of demographic decline, generation renewal problems and land abandonment. Furthermore, as in the case of Mediterranean agro-pastoralism described by Farinella and Nori (Chapter 5), it appears that the vulnerable conditions of migrants are furthered by the scarce presence of public control and trade unions in rural areas and the constant presence of a 'reserve army swelled by new migratory waves [that] consolidates exploitative conditions, as evidenced by the continuous replacement of migrant labour with new arrivals and different ethnic groups' (Farinella and Nori, Chapter 5, 71). However, these are processes that vary greatly across rural spaces and thus influence the everyday conditions for workers in different ways; the rural labour migration phenomenon unfolds uniquely across what we are here calling rural space (see Chapter 1 for an explanation of the use of this term in this way).

Nonetheless, a common trait of the proximate structures in the case of the rural labour migration phenomenon appears to be their existence independent of our agents in focus, the migrants. For the migrant worker, the migration regimes, labour conditions, and local community is experienced as a given; they are the ones least able within this labour context to modify and change these conditions but have to adjust to them as they are; that is, as they have been formed by other and more powerful agents in the localities.

In many cases, these structures are supported by cultural and ideological frames that work to fortify them. For instance, employers of migrant workers may internalise the ideas above and, despite numerous accounts of the exploitative nature of the work they provide, emphasise the positive aspects of their relationship to their workers. Examining such 'hegemonic discourses' in the strawberry industry in the US, UK, and Norway, Rye and Scott (Chapter 9) note how employers refer to migrants' 'dual frames of reference' and invoke what the migrants could earn at home to justify what are poor wages in the host country. These employers believe themselves to provide 'good work' for the migrants and, for instance, emphasise how the benefits are taken home to ensure 'future prosperity' rather than problematise their relatively deprived position in the host community. In this way they conceptualise migrant workers as genuinely different, and thus both in need of and less deserving of the working and living standards they take for granted for themselves and other 'locals.'

The employers in Farinella's and Nori's chapter are more explicit in their construction of a hierarchy between employers and workers, and they talk of the backwardness of their immigrant shepherds, which is an 'imagined 
backwardness' [that] serves the stockowner to assert a sort of moral, cultural, and technical superiority over the immigrant worker, which legitimises the low wage demand for obedience (Chapter 5, 80).

Other ideological frames include assumptions held on the part of some employers, migrants, and locals alike that local people will not do the work migrants do in these rural areas. This functions as a self-fulfilling prophecy par excellence. For example, as a result of Brexit, the British government announced it would like to encourage the local workforce. However, the only actual policy suggested so far to help replace recruitment is a seasonal and temporary scheme similar to the former Seasonal Agricultural Workers Scheme. This sort of scheme is known to lead to instability, exclusion, and marginalisation (Halfacree, Chapter 12). Contrary to the above, there are also some deeply held assumptions on the part of local populations that migrants are a drain on local resources, taking jobs locals could do, and requiring schooling and other services that might be in high demand (Halfacree, Chapter 12).

In summary, there are distinctive and more proximate structural features which are unique to our understanding of the experiences, practices, and outcomes of international labour migration to Europe's rural areas. First, despite the diversity of labour migration regimes, they are generally demanddriven, addressing employers' assumed need for labour as opposed to addressing workers' need for good working conditions. Second, labour migration regulations and practices consistently overlook (and work to consolidate) rural labour migrants' poor working and living conditions. Third, specific features of rural societies, such as demographic decline, generation renewal problems, land abandonment, and harsh territories, as discussed in many of the chapters, are related to the hardships migrants experience. Crucially, these localised structural features are internalised, enacted, and performed by a range of actors, including local employers, local people, and even the migrants themselves, to produce marginalisation and subordination. Thus, as with wider structures and despite their spatial heterogeneity, proximate structures generally appear to contribute to the shaping of poor work and life conditions.

\section{iii) Migrants' aspirations, expectations, and accommodations}

Internal structures are those taken-for-granted ways of doing things, ways of thinking, deeply held normative assumptions, and even embodied habits that shape all our lives and that, in turn, have been shaped by past experiences. Bourdieu's $(1990,53)$ term 'habitus' is one of the clearest ways to think about internal structures, as 'systems of durable, transposable dispositions, structured structures predisposed to function as structuring structures.' The migrants that feature in the chapters here are not homogeneous: their lives have been moulded by education, class, gender, age, diverse cultural orientations, and experiences, into deeply embodied dispositions, or habitus. 
Their experiences after migration are, in turn, influenced and shaped by these internal structures in a variety of ways as they confront the new fields of their host societies (Stones et al. 2019), and especially the structural conditions outlined in the previous sections. For migrants, internalised structures include assumptions about the destination, the work one is moving for, the way of life assumed to be achievable, and even the plans for the future that have been shaped by prior migrants and their recreated experiences, as well as by other media of communication. Again, we outline, from the material in this edited volume, three features we find of particular relevance in the analysis of the rural labour migration phenomenon in Europe.

First, our agents in focus, the migrants in these chapters, have hopes, dreams and aspirations that are forged over time and tempered by the realities of those who have gone before, or their own experiences, and knowledge. Despite conditions pointing to the contrary, many migrants are hopeful for better futures, and for settled and good lives. Aure's and Riabova's chapter (Chapter 10) is especially rich in examples of such internalised structures. The migration from Teriberka, in Russia, to Båtsfjord, in Norway, was inscribed with tropes promising a better future from the outset. The 'candidate' migrants were 'interviewed and carefully selected,' which in itself must have raised hopes that this would be a positive experience. Furthermore, migration can be a very emotional experience; while 'they hoped for a better life' and 'it was so exciting,' Aure's and Riabova's migrants also experienced fear and apprehension. For some migrants, let's remember, there is optimism for the future, despite the fact migrants often leave family behind, and often have uncertain futures. This points to the importance of understanding migrants' actions as much more complex than a purely rational and instrumental interpretation might suggest. Their hopes for an imagined future can outweigh their factual knowledge about other migrants' hardships, and they therefore 'willingly' enter into migration trajectories despite knowing about the likely challenges, including exploitative work and life conditions, which are lying ahead.

Second, there are some populations for whom we could talk of a migration habitus: the migrants' prior internalisation of migration as a potential strategy, and their embodied and tacit adjustment to the parameters of action in their social contexts. As Bourdieu (1990) reminds us, objective constraints tend to shape what people aspire to. They follow routes laid down by earlier migrants, pursuing established networks and paths (and of course some pursue new routes they hear of through different media). In other words, where migrants go, their choices, and how they assume life will be when they get there, how long they expect to stay and so on, is shaped by their own and others' prior experiences, and the stories and discourses that frame those experiences.

Stachowski and Fiałkowska, for example, illustrate how Polish migration to Norway, in this case, is marked by high levels of cross-border mobility, probably because some Polish people have by now developed the habit of migrating (inscribed into the habitus, if not yet into practice) and, because Poland is not 
too distant from Norway, the habit of regular return visits. Yet, these Polish migrants also dreamed of settling and making a new home. Alternatively, the German case they speak of is 'an example of a seasonal, temporary labour migration from Poland that stretches back to the mid-nineteenth century.' Originating from an area in Poland where 'seasonal migration was a widely popular livelihood strategy,' it too has indubitably acquired the sense of a habit, with 'traits of permanence' (Stachowski and Fiałkowska, Chapter 7, 105). Similarly, as demonstrated in many of the chapters, and as a result of the regimes outlined above, many migrants develop transnational social practices spanning state borders that work to mitigate the negative experiences abroad.

Third, as result of their migration practices and experiences, migrants come to accommodate to the demanding nature of their working and home lives. In other words, they develop identities that are coherent with, and even reinforce, the 'normalisation' of the conditions within which they find themselves. Most of the migrants in the pages of this volume internalise the fact that work is often hard, and that life is challenging. Irrespective of dreams of settlement, some learn that in reality their migration needs to be cyclical, for example in Saluzzo, Italy, where the 'local administration systematically has closed the formal camp and dismantled the informal settlements at the end of each agricultural season' (Brovia and Piro, Chapter 4, 63). They are aware they are being exploited, and of course this will affect how they behave when they arrive. As Stachowski and Fiałkowska tell us, migrants often see themselves as marginal in the rural communities, although they are sometimes 'also conscious of their pivotal role' in the local economy, which may of course empower them at some stage. Similarly, the migrants in this book often share the assumptions discussed above that they are doing work that it is believed locals will not do.

In summary, our agents in focus, our migrants in these chapters, have hopes, dreams, and aspirations that are forged over time and tempered by the realities of those who have gone before, or their own experiences and knowledge. Many of these had already acquired a migration habitus, internalising and embodying migration as a potential strategy, transnationalism as a social practice, and other tacit adjustments to the parameters of action in their social contexts. Finally, we also note that despite any initial hopes or expectations to the contrary, as a result of their migration practices and experiences, migrants begin to accommodate to the demanding nature of their working and home lives.

\section{iv) Rural migrants' agency}

We now turn to what the ongoing practice of migration is like for the migrant workers in the pages of this book. This section is about the here and now, the constantly changing present - the present continuous - in which our migrants live and act. In a framework informed by strong structuration theory, active agency takes the shape of individual reflexive reactions to 
specific circumstances, which are always to some extent circumscribed by previous events and experiences, and by ongoing contingencies. As Morawska (2009) reminds us, migration is an unsettling experience, causing people to reconsider options and re-evaluate resources. Furthermore, we should not forget that habituses (or otherwise conceptualised internal structures) are malleable, transposable, and open to be amended in the practice of daily life. Stones (2005) developed the ontological concept of conjuncturally specific internal structures (CJS) as a means for better comprehending the daily interaction of structure and agency. CJS become relevant at the point of action, when agents confront specific sets of circumstances, or are in the position to make certain choices, shaped by their imagination of how things could be different. In turn, CJS are shaped in the everyday by the fact that all agents are at any time located within sets of relationships, or communities of practice (Wenger 1998).

The volume's chapters demonstrate how migrants are sometimes able to take advantage of conditions that arise to enable improvement in their lives: they are certainly not passive subjects of structural forces. Fratsea and Papadopoulos (Chapter 3) focus expressly on the agency of Romanians in Greece, who developed individual and family strategies to improve their quality of life and their social situation, offering them some resilience during the economic crisis in Greece. Some Romanians, despite difficult conditions, have been able to open Romanian restaurants, transport companies, and Airbnb businesses. Interestingly, the authors argue that much of the resilience shown by these migrants arrives through earlier coping mechanisms, including building strong social networks. These new businesses may not amount to wholescale structural change for Romanian migrants as a whole, but it still implies new outcomes for future migrants who can build on the contacts, knowledge, expertise, and aspirations of those who have been able to exercise agency to effect positive change (and see O'Reilly 2018).

Similarly, Stachowski and Fiałkowska (Chapter 7, 105) say the Polish migrants they studied 'are not simply victims of oppressive structural forces, but also display an array of agentic competences, making sense of their situation, achieving a degree of control over their lives, and being able to pursue their life plans.' Some are able to aspire to stay longer, to settle, and then to work towards achieving that, especially in Norway: the average time living in the community for Stachowski's participants was six and a half years. Farinella and Nori's (Chapter 5, 76) shepherds were able to demonstrate 'high degrees of mobility, often moving from one farm to another' in pursuit of better conditions. Some engage in practices such as selling products from a vegetable garden and earning a little on the side by fixing things.

However, agency amounts to more than actors' strategic actions. At times, it is exactly what our agents in focus do that contributes, over time and space, to the reproduction of their own marginalisation and subordination. For example, once Romania joined the EU and gained the right to 
freedom of movement, the recruitment processes of Romanians to Spain were informalised, relying on migrants' own networks. Yet these migrants themselves reproduced the former practices of temporary, circular migration, by continuing to assume this was the way to migrate in this context and repeating the patterns of earlier trends. Şerban et al. (Chapter 2, 34) argue this was the result of 'the power of social networks made up of migrants who learned to embody and enact employers' demands.'

To return to the examples above, while some Romanians in Greece have opened new businesses and broken away from exploitative rural labour, others continue to engage in temporary migration as a household support strategy or survival strategy. These migrations continue to support exploitative practices. Similarly, Stachowski and Fiałkowska (Chapter 7, 109-110) talk of how Polish migrants learn to be 'ideal' workers, to be resilient and obedient at work, 'we came here to work, not to take a rest' was an oftrepeated phrase, which helped to build resilience in the face of poor accommodation, a demanding job, the demeaning treatment of workers, and 'insecurity related to future employment translates into an intensification of work and self-exploitation.'

In Halfacree's chapter, migrants in the UK exhibit characteristics expected of them in line with notions of the good rural worker, including: 'a generally strong work ethic and record of getting jobs done, a large degree of selfsufficiency.' And Farinella and Nori (Chapter 5) admit that the shepherds' strategies, discussed above, in fact amount to little more than what Scott (1985) referred to as 'weapons of the weak,' everyday forms of resistance that work more as coping mechanisms than providing real structural change. The shepherding migrants learn to be the good migrants their employers want, and these everyday practices - while designed to limit subordination - in fact serve to legitimate their exploitation and lack of power to effect profound change. In what amounts to an excellent analysis of the interaction of structure and agency over time, Farinella and Nori (Chapter 5, 82) argue:

The shepherd is a 'good worker' only as long as he is docile, obedient, and willing to accept low wages. The migratory paths remain circular and international migrants move from one farm to another, from one territory to another; they cannot think of shepherding as a 'career' with opportunities for social mobility, but only as a precarious and uncertain employment and temporary source of income.

The Thai berry pickers in Tollefsen et al. (Chapter 8) were told they were legally entitled to a guaranteed wage, but were then asked to choose between that or a piece rate which, though it promised to offer more, often meant in practice migrants ended up with less than the guaranteed wage. So, while they may have overtly chosen to be paid per kilo, they did it with the hope of earning more, while ending up with less. 
In conclusion, many of the chapters in this edited volume are able to offer examples in which labour migrants in Europe's rural regions are sometimes able to take advantage of conditions that arise to enable improvement of their conditions. It is not our intention here to strip our agents in focus of their strategic agency. Nevertheless, it is clear that it is often through their own small, daily practices that they also contribute to the reproduction of the conditions under which they are marginalised, exploited, and subordinated. This is because their own agency, as with all agents involved in rural labour migration, is shaped by what has gone before through the constraints of external and internalised (and learned) structures.

\section{v) The outcomes: newly (re)formed external and internal structures}

What people do and the ways in which they interact will have an effect for subsequent perceptions, expectations, habits, ways of doing things, and agency. In turn, these shape communities of practice (networks, groups, relationships), and both local and broader structures are reproduced or transformed, to varying degrees, over space and time. Outcomes of structuration processes can be intended or unintended and can lead to innovation or consolidation. Outcomes, as we shall see here, take the shape of external and internal structures, of practices, and communities.

The chapters in this edited volume have sometimes been able to draw attention to small acts of agency that have led to new patterns or arrangements. We witness a few, minor positive changes for our agents in focus, the migrants. For instance, some of the Polish migrants in Norway settle more permanently, are joined by their families, and see an improved financial situation. Nevertheless, their opportunities for further enhancement, for example by moving into other work, appears limited. In the UK, some migrants put into practice their imaginings of the rural idyll and achieve some sense of settlement. However, since the 2016 Brexit referendum, migrants are apparently feeling less comfortable, less settled, and less accepted (Halfacree, Chapter 12).

However, very little of this change is transformational and the overwhelming emphasis in the chapters is on subordination and marginalisation of migrants. As Șerban et al. (Chapter 2) argue, employers and other decision-makers often relate to migrants as labour rather than as human beings. They mask exploitation, even to themselves, with a rhetoric of good work, invoking the 'good migrant.' In Chapter 10 by Rye and Scott, despite their recognition of the harsh nature of work in the strawberry industry, the employers first and foremost emphasised the positive aspects of the work and their role, talking of how good the work they provide is, and how working well and producing good harvests is to the benefit of employers and workers alike. This paternalistic attitude in which they view themselves as good and socially responsible employers, functions to reproduce, and also mask, labour arrangements 
that foster marginalisation and exploitation. Similarly, the way in which food and accommodation are provided 'in kind' as a way of offering savings for immigrant shepherds (Farinella and Nori, Chapter 5, 78) could instead be interpreted as 'a governmental power on migrant life' (Foucault 1975), in which 'the farmer's family establishes what and when to eat, how and when to sleep, how to dress, and when to wash.'

In some cases, what appeared to be a transformative form of agency was indeed conjuncturally specific internalised structures reproducing or causing negative outcomes. Stachowski and Fiałkowska talk of the awful conditions Polish migrants suffer in Germany, including seclusion in camp accommodation, frequent power cuts, and restricted access to storage, water, and washing facilities. But these migrants themselves continually compare their lives with home and this serves to enable them to rationalise their own marginality. In other words, they are somewhat complicit in their own marginalisation. This is a form of what Bourdieu has called symbolic violence, which:

Represents the way in which people play a role in reproducing their own subordination through the gradual internalisation and acceptance of those ideas and structures that tend to subordinate them. It is an act of violence precisely because it leads to the constraint and subordination of individuals, but it is also symbolic in the sense that this is achieved indirectly and without overt and explicit acts of force or coercion.

(Connolly and Healy 2004, 15)

In the end, what these migrants work towards changing is minimal, with the focus more on making things easier to bear than on actually shaping and acting on desires (see Stones 2009). As Fratsea and Papadopoulos (Chapter 3, 40) acknowledge, migrants always have to fit agency to conditions: their 'repertoire of strategies and practices,' their aspirations, hopes and dreams, are always shaped over time and space by the opportunity structures they confront.

\section{Conclusion: the reproduction of the exploitative nature of rural labour}

In this chapter we have outlined a practice story of international labour migration to Europe's rural regions which provides unique insights into the perpetual reproduction of exploitative wage, working, and living conditions of migrant workers. This, we argue, is the outcome of the dynamic interplay between structural properties of the rural labour migration phenomenon and the agency of migrants, and other agents involved in the making of the phenomenon, as practices that take place over space and time. In other words, our account reveals how the daily practices of agency (of all agents involved in the process) work to (re)produce generally exploitative working conditions. 
There are three distinctive (upper level/macro) structural features that are unique to our understanding of the experiences, practices, and outcomes of international labour migration to Europe's rural areas. These are: an increasing reliance on migrant labour as part of the changing fabric of state borders; increasing levels of polarisation, competition, and exploitation in the context of a general process of industrial restructuring in Europe's rural industries; and the distinctive characteristics of rural society that tend to be invoked to justify the exploitation and marginalisation of migrant workers. Furthermore, farm work, agricultural work, and land-based work are 'normalised,' or unquestioningly deemed, as more precarious than work in other industries. The very nature of seasonal and land-based work as temporary and precarious is itself used to justify exploitation. This normalisation affects decisions made on the part of agents with power to effect change, for example, it is considered more difficult to ensure workers' rights in these areas.

There are three further distinctive (more proximate /meso-level) structural features that are unique to our understanding of the experiences, practices, and outcomes of international labour migration to Europe's rural areas. First, labour migration regimes are generally demand-driven, addressing employers' assumed need for labour as opposed to addressing workers' need for good working conditions. Second, labour migration regulations and practices consistently overlook rural labour migrants' poor working and living conditions. Third, specific features of rural societies, such as the nature of rural work, depopulation, land abandonment, and harsh territories, are viewed as inimical to improved conditions for migrants. Crucially, these localised structural features are internalised, enacted, and performed by a range of actors, including local employers, local people, and even the migrants themselves, to produce social and spatial marginalisation, and subordination.

The migrants in these chapters have aspirations for their migration that are tempered by the realities of those who have gone before and their own experiences, but still can be ambitious, hopeful, and emotional. Some had acquired a migration habitus, internalising and embodying temporary or seasonal migration as a potential strategy, transnationalism as a social practice, and other tacit adjustments to the parameters of action in their social contexts. Others dreamed of settlement and new lives in new destinations. But, over time, migrants begin to accommodate to the demanding nature of their working and home lives.

Several of the chapters in this edited volume offer examples in which labour migrants in Europe's rural regions take advantage of conditions that arise to enable improvement of their conditions. Nevertheless, as the chapters in this edited volume have indubitably shown, it is also clear that it is often through their own small, daily practices that they come to unwittingly contribute to the reproduction of the conditions under which they are marginalised, exploited, and subordinated. 
In the end, the chapters in this edited volume have shown that migrants are only able to effect minimal change, with the focus more on making things easier to bear than on actually having the power to shape or act on desires (see Stones 2009). As Fratsea and Papadopoulos (Chapter 3) acknowledge, migrants always have to fit agency to conditions, their 'repertoire of strategies and practices,' their aspirations, hopes, and dreams, are always shaped over time and space by the opportunity structures they confront in their daily lives, communities, and practices.

Our practice story of international labour migration to Europe's rural regions concludes thus: macro-level conditions have developed under which change for the better, for migrants, is difficult or impossible to achieve; meso-level developments continue to operationalise assumptions that labour migration is necessarily harsh and that employers need to be protected; employers and other powerful agents embody the normalisation of practices; and even the migrants themselves come to accommodate or reproduce through their daily practices the conditions for their own marginalised and subordinated status.

\section{Acknowledgements}

The chapter project, is the result of the 2017-2022 Global Labour in Rural Societies research project financed by the Norwegian Research Council (grant no. 261854/F10). The authors wish to thank the external reviewers for their constructive comments on the manuscript.

\section{References}

Benson, M. and K. O'Reilly. 2018. Lifestyle Migration and Colonial Traces in Malaysia and Panama. Basingstoke: Palgrave Macmillan.

Bock, B., G. Osti and F. Ventura. 2016. 'Rural Migration and New Patterns of Exclusion and Integration in Europe.' In The Routledge International Handbook of Rural Studies, edited by M. Shucksmith and D. Brown, 71-84. New York, Routledge.

Bourdieu, P. 1990. The Logic of Practice. Cambridge: Polity.

Castles, S. 2006. 'Guestworkers in Europe: A Resurrection?' International Migration Review, 40(4): 741-766.

Connolly, P. and J. Healy. 2004. 'Symbolic Violence, Locality and Social Class: The Educational and Career Aspirations of 10-11-year-old Boys in Belfast.' Pedagogy, Culture and Society 12(1): 15-34.

Corrado, A., C. de Castro and D. Perrotta, eds. 2016. Migration and Agriculture Mobility and Change in the Mediterranean Area. London, Routledge.

Doeringer, P.B. and M. Piore. 1971. Internal Labor Markets and Manpower Analysis. New York: D.C Heath and Company.

Emirbayer, M. and A. Mische. 1998. 'What is Agency?' American Journal of Sociology 103(4): 962-1023. 
Foucault, M. 1975. Surveiller et Punir [Discipline and Punish]. Paris: Gallimard.

Gertel, J. and S.R. Sippel, eds. 2014. Seasonal Workers in Mediterranean Agriculture. Abingdon, Routledge.

Greenhalgh, T., R. Stones, R. and D. Swinglehurst. 2014. 'Choose and Book: A Sociological Analysis of Resistance to an Expert System.' Social Science and Medicine 104: 210-219.

Holmes, S.M. 2013. Fresh Fruits, Broken Bodies. Migrant Farmworkers in the United States. Berkeley: California Series in Public Anthropology.

Lave, J. and Wenger, E. 1991. Situated Learning: Legitimate Peripheral Participation. Cambridge: Cambridge University Press.

Morawska, E. 1996. Insecure Prosperity: Small-town Jews in Industrial America. 1890 1940. Princeton, NJ: Princeton University Press.

Morawska, E. 2009. A Sociology of Immigration: (Re)making Multifaceted America. Basingstoke: Palgrave.

O'Reilly, K. 2012. International Migration and Social Theory. Basingstoke: Palgrave.

O'Reilly, K. 2018. 'The British on the Costa Del Sol Twenty Years On: A Story of Liquids and Sediments.' Nordic Journal of Migration Research 7(3): 139-147.

Rye, J.F. 2017. 'Negotiating Neoliberalism: Informalisation and Reformalisation of Industrial Relations in Norway's Agricultural Industry in the 21st Century.' Population, Space and Place 23(7): unpaginated. DOI:10.1002/psp.2042.

Rye, J.F. and J. Andrzejewska. 2010. 'The Structural Disempowerment of Eastern European Migrant Farm Workers in Norwegian Agriculture.' Journal of Rural Studies 26(1): 41-51.

Rye, J.F. and S. Scott. 2018. 'International Labour Migration to/in rural Europe: A Review of the Evidence.' Sociologia Ruralis 8(4): 928-954.

Scott, J.C. 1985. Weapons of the Weak. Everyday Forms of Peasant Resistance. New Haven, CT: Yale University Press.

Stones, R. 2005. Structuration Theory. Basingstoke: Palgrave Macmillan.

Stones, R. 2009. 'Power and Structuration Theory.' In The Sage Handbook of Power, edited by S. Clegg and M.Haugaard, 89-107. London: Sage.

Stones, R., K. Botterill, M. Lee and K. O'Reilly. 2019. 'One World is not Enough: The Structured Phenomenology of Lifestyle Migrants in East Asia.' British Journal of Sociology 70(1): 44-69.

Wenger, E. 1998. Communities of Practice: Learning, Meaning, and Identity. Cambridge: Cambridge University Press. 